\title{
KEBIJAKAN PEMERINTAH DESA SEKAR DALAM PELESTARIAN TRADISI “CEPROTAN"
}

\author{
Muhammad Khoirul Mustaqim \\ Krishan Yudi Nugroho \\ Dian Suluh Kusuma Dewi \\ Program Studi Ilmu Pemerintahan, Fakultas Ilmu Sosial dan Ilmu Politik, \\ Universitas Muhammadiyah Ponorogo \\ khoirul.mustak@gmail.com \\ Krishanyudinugroho@gmail.com \\ suluh.dian@gmail.com
}

\begin{abstract}
Abstrak
Di Indonesia memiliki banyak tradisi budaya salah satunya yaitu, tradisi Ceprotan. Tradisi ini adalah upacara bersih desa yang dilaksanakan di Desa Sekar Kecamatan Donorojo Kabupaten Pacitan. Tujuan utama dari diselenggarakannya tradisi ini yaitu keselamatan desa dan menjauhkan dari mara bahaya. Tradisi ini diselenggarakan setahun sekali, yaitu pada bulan Longkang atau Selo (DzulQa'adah / Dulkangidah) hari pasaran Senin Kliwon atau pada hari Minggu Kliwon sebelum menjelang matahari terbenam. Penelitian ini mendiskripsikan asal-usul Ceprotan dan kebijakan Pemerintah Desa Sekar dalam pelestarian tradisi Ceprotan. Penelitian ini menggunakan metode adalah deskriptif kualitatif. Dengan teknik pengambilan data dari observasi dan studi kepustakaan seperti surat kabar, majalah, dokumen dan media informasi lainnya. Dapat diambil kesimpulan bahwa kebijakan yang diambil pemerintah sangat berperan dalam pelestarian kebudayaan tradisional dan menghadapi hambatan - hambatan yang terjadi dalam proses pembangunan pariwisata.
\end{abstract}

Kata Kunci : Tradisi Ceprotan, Pelestarian, Desa Sekar.

\section{Abstract}

In Indonesia, there are many cultural traditions, one of which is Ceprotan tradition. This tradition is a clean ceremony of the village that is held in the Village district Donorojo, Pacitan Regency. The main purpose of this tradition is the safety of the village and to avoid danger. This tradition is held once a year, namely in the month of Longkang or Selo (Dzulqa'adah/Dulkangidah) Market day Monday Kliwon or Sunday Kliwon before sunset. This study described the origins of Ceprotan and the policy of the Sekar village government in preserving the tradition of Ceprotan. This research using methods is a qualitative descriptive. With the techniques of retrieving data from observations and literature studies such as newspapers, magazines, documents and other media information. It can be inferred that the policy taken by the Government plays a role in preserving 
traditional cultures and facing the barriers that occur in the process of tourism development.

Keywords : Ceprotan Tradition, Conservation, Sekar Village.

\section{PENDAHULUAN}

\section{A. Budaya dan Tradisi}

Kebudayaan memiliki arti keseluruhan gagasan dan karya manusia yang harus dibiasakan dengan mempelajarinya serta seluruh dari hasil budi pekertinya. (Utara 2008) Sedangkan menurut pendapat Ki Hajar Dewantara kebudayaan dapat diartikan suatu buah budi manusia. Hal ini hasil perjuangan manusia terhadap dua pengaruh kuat, yaitu kodrat zaman dan kodrat alam. (Apriliani Fitria and Aniriani Wilda 2017) Kebudayaan adalah suatu bukti kejayaan hidup manusia dalam menghadapi segala rintangan dan kesulitan di dalam kehidupannya guna untuk mencapai keselamatan dan kebahagiaan bersifat tertib dan damai. Dapat dikatakan bahwa kebudayaan memuat sistem pengetahuan yang meliputi sistem ide atau gagasan yang terdapat dalam pikiran manusia, selanjutnya kebudayaan juga bersifat abstrak. (Rahmawati 2015)

Istilah kebudayaan berasal dari bahasa sansekerta buddayah, yang berasal dari bentuk jamak dari kata buddhi, yang memiliki arti budi atau akal. Dengan demikian, kebudayaan bermakna sesuatu hal yang berhubungan dengan akal. (Tradisi et al. 2015) Ahli antropologi Edward Burnett Tylor mendefinisikan kebudayaan secara sistematis dan ilmiah adalah, yang tetulis dalam bukunya: "Primitive Culture", (Edward Burnett 1871) kebudayaan merupakan kesatuan yang kompleks, di dalamnya terdiri dari pengetahuan, kepercayaan dan agama, kesenian, moralitas, hukum, adat - istiadat, dan lainnya yang berhubungan dengan masyarakat, serta kebiasaan yang diperoleh manusia sebagai bagian dalam anggota masyarakat. (Tradisi et al. 2015)

Tradisi berasal dari Bahasa Latin Traditio yang berarti diteruskan. Tradisi adalah kebiasaan dalam suatu masyarakat yang dilakukan secara turun temurun. Dalam artian yang lebih sederhana tradisi adalah kebiasaan dari masyarakat yang 
biasanya berasal dari suatu wilayah negara, agama, kebudayaan, waktu atau suku yang sama dan sudah ada sejak dahulu kala yang menjadi bagian dari kehidupan sehari - harinya. Suatu tradisi dapat punah apabila tidak adanya informasi yang diwariskan dari generasi ke generasi seterusnya baik yang tertulis maupun secara lisan. (Robert 2015)

Bastomi (1984 :14) menjelaskan bahwa tradisi menjadi inti dari suatu kebudayaan. Apabila tradisi itu hilang akan ada kemungkinan kebudayaan itu akan berakhir saat itu juga. Setiap sesuatu yang menjadi tradisi biasanya telah teruji keefektifitas dan keefisiensinya. Tingkat efektifitas dan efisiensi akan selalu menyesuaikan dengan perkembangan kebudayaan yang ada. Dalam menyelesaikan persoalan atau permasalahan berbagai sikap dan tindakan akan diambil namun kalau tingkat efektifitas dan efisiensinya rendah akan ditinggalkan pelakunya dan hal tersebut tidak akan pernah menjadi sebagai tradisi. Sebuah tradisi akan tetap dipakai apabila cocok dan relevan sesuai dengan situasi dan kondisi masyarakat pewarisnya. (Pesantren, Abdul, and Pacet 2019)

\section{B. Masyarakat}

Masyarakat adalah kumpulan orang yang hidup bersama dalam suatu kawasan tertentu dalam waktu yang cukup lama dan bersifat kekal yang menempati kawasan tertentu, masyarakat memiliki kebudayaan yang terjalin satu sama lain. Manusia dengan kemampuan yang dimilikinya dapat memilih kegiatan apa yang sesuai dengan kemungkinan dan peluang yang telah diberikan oleh alam lingkungannya. (Tradisi et al. 2015)

Masyarakat Indonesia memiliki berbagai keanekaragaman suku bangsa, hal itu membuat Indonesia memiliki berbagai macam tradisi, adat - istiadat, norma dan nilai - nilai serta tatanan yang berbeda setiap daerah. Masyarakat suatu daerah akan berusaha mewariskan tradisinya kepada generasi penerusnya agar tidak punah.

Kabupaten Pacitan mendapat julukan kota 1001 goa, karena terdapat banyak goa - goa yang menarik untuk dijadikan tempat wisata, selain goa terdapat banyak pantai - pantai yang indah dan tersembunyi di pesisir selatan. Upacara adat yang ada juga menjadi salah satu daya tarik wisatawan untuk datang ke 
Pacitan. Salah satu tradisi yang menjadi khas di Pacitan yaitu Ceprotan (bersih desa) upacara ini dilaksanakan di Desa Sekar Kecamatan Donorojo Kabupaten Pacitan. Tradisi tersebut sebagai wujud serta upaya membuktikan rasa syukur terhadap Tuhan. Tradisi Ceprotan menjadi upacara adat yang dilaksanakan sebagai wujud rasa syukur dan membersihkan desa dari bencana. Masyarakat desa Sekar sendiri meskipun telah menerima kepercayaan islam dalam kehidupan sehari - harinya, namun mereka masih tetap mempertahankan warisan nenek moyang untuk menjaga tradisi supaya tetap terpelihara dan tidak punah oleh perkembangan zaman.

\section{Kebijakan Pemerintah}

Pemerintah daerah berperan penting dalam proses perencanaan kebijakan dan tahap pelaksanaannya, hal itu berguna untuk menghindari permasalahan. Pemerintah daerah merupakan pihak yang berwenang dalam mendorong kemajuan suatu daerah dalam bidang kebudayaan. Menurut Sri Edi Tjahjo Kuntjoro sebagai wujud tanggungjawab pemerintah dalam hal pelestarian budaya tersebut adalah dengan menerbitkan undang-undang yaitu undang - undang Cagar Budaya, meskipun dalam proses pengaplikasiannya undang - undang cagar budaya ini tidak serta merta mudah dilaksanakan secara maksimal. (Nunggalsari and Soebijantoro 2018)

Kebijakan menurut Thomas R. Dye adalah whatever goverments choose to do or not do. Dapat diartikan, bahwa apapun kegiatan pemerintah baik yang eksplisit maupun implisit merupakan kebijakan. (Nunggalsari and Soebijantoro 2018) Kebijakan terdapat 3 elemen yaitu identifikasi, taktik dan strategi serta ketersediaan input. Identifikasi terdiri dari tujuan yang ingin dicapai, taktik atau strategi terdiri dari berbagai langkah untuk mencapai tujuan yang ingin dicapai dan ketersediaan berbagai input untuk memungkinkan pelaksanaan secara nyata taktik dan strategi sudah ada. (Nunggalsari and Soebijantoro 2018)

Metode penelitian dalam tulisan ini menggunakan pendekatan deskriptif kualitatif. Teknik pengumpulan data yang digunakan dengan cara studi kepustakaan, majalah, surat kabar, buku- buku, dokumen - dokumen dan media informasi lainnya yang ada keterikatan dengan masalah yang ingin diteliti dan 
wawancara dengan narasumber yang terpercaya secara mendalam serta observasi yaitu mengamati secara langsung obyek yang di teliti. (Ika Monika 2017)

Dalam penelitian ini menggunakan analisi data kualitatif. Bogdan dan Guba menyebutkan bahwa penlitian kualitatif atau naturalistic inquiry merupakan tata cara penelitian untuk mengdapatkan data deskriptik berupa kata - kata dari lisan maupun tertulis dari individu - individu serta tingkah laku yang diamati. Pendekatan kualitatif dirasa lebih mampu mendeskripsikan suatu gejala atau fenomena soaial yang terjadi di masyarakat. (Nunggalsari and Soebijantoro 2018) Teknik pengumpulan data yang digunakan dengan cara yang pertama dengan wawancara, yang kedua dengan observasi dan dokumentasi. Pengumpulan data bila dilihat dari sumber datanya dapat menggunakan sumber data primer dan sumber data sekunder dan dokumentasi untuk dijadikan sebagai data pelengkap dari wawancara dan observasi.

\section{PEMBAHASAN}

\section{A. Sejarah Ceprotan}

Upacara tradisi Ceprotan ini merupakan ritual adat bersih desa sebagai wujud membersihkan desa dari marabahaya dan juga untuk mengenang jasa pendahulu Desa Sekar yaitu Dewi Sekartaji, Panji Asmorobangun dan Ki Godeg. Tradisi ini hanya diadadakan di Dusun Krajan Desa Sekar Kecamatan Donorejo. Awalnya kegiatan upacara ini hanya dilakukan oleh warga setempat dengan sukarela dan gotong royong antar warga, namun setelah dikemas lebih menarik menjadi objek pariwisata pemerintah kabupaten Pacitan dan Dinas Pariwisata kabupaten Pacitan ikut andil dan penyelenggaraannya. (Tradisi et al. 2015)

Gambar. 1 (Peraga yang menjadi Dewi Sekartaji

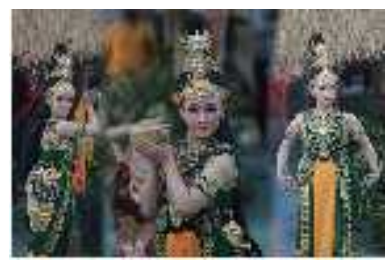

.http://wap.mi.baca.co.id/35064998?origin=relative \&pageId $=7 e 22 a 0 e d-2 b 81$ 4c19-b1c7-ea952ab4c2e5\&PageIndex $=2$ ) 
Ada berbagai macam asal usul cerita Ceprotan, namum yang paling terkenal ada 2 versi. Versi yang pertama, Ceprotan merupakan wujud membersihkan desa, dilaksanakan dengan menggelar upacara untuk menolak bala dari malapetaka desa. Di versi ini pada jaman dahulu ada peristiwa pertemuan Ki Godeg dengan Dewi Sekartaji di sumber mata air tempat mandi mereka. Pertemuan itu terjadi di waktu surup ( magrib ). Dewi Sekartaji saat itu sedang dalam perjalanan mencari kekasihnya Panji Asmorobangun. Setelah itu Ki Godeg mengajak Dewi Sekartaji untuk menginap dirumahnya namun peristiwa ini diketahui oleh salah seorang saudara Ki Godeg yang disembunyikan namanya. Ki Godeg ini tertarik dan berniat melamar Dewi Sekartaji, namun ketika saudara Ki Godeg kerumah, ternyata dia sudah pergi sejak pagi. Akhirnya muncul pikiran jahat dari saudara tersebut dan menuduh Ki Godeg di depan istrinya bahwa itu tadi adalah istri simpanan Ki Godeg yang dirahasiakan selama ini. Tiba - tiba dengan spontan saudara Ki Godeg tersebut melempar kelapa yang dibawanya untuk seserahan dan terjadilah lempar - lemparan kelapa diantara keduanya. Berawal dari kejadian inilah filosofi saling melempar kelapa menjadi simbol untuk menolak bala dan marabahaya, sekaligus simbol membersihkan diri dari pikiran dan perbuatan buruk. (Permadi 2019)

Di versi yang kedua ini Ceprotan dilakukan untuk mengenang serta mengahargai jasa Dewi Sekartaji yang telah melakukan babat hutan untuk dijadikan Desa Sekar dan menjadikannya tanah yang subur. Pada awalnya Desa Sekar adalah sebuah tempat yang kering dan gersang dan sulit untuk mendapatkan sumber air, pada saat itu Dewi Sekartaji yang bertemu Ki Godeg dan meminta bantuannya untuk mencarikan air untuknya. Tapi mereka hanya menemukan satu kelapa muda yang kemudian kelapa muda itu dibanting oleh Dewi Sekartaji dan keluar air dari tanah sampai akhirnya menjadi sumber mata air. (Permadi 2019)

Cerita versi kedua inilah yang sampai saat ini paling banyak dipercayai masyarakat setempat yang menjadikan upacara ini dianggap sakral. Upacara ini diyakini warga mampu menjauhkan desa dari segala marabahaya dan bencana serta melancarkan kegiatan pertanian. (Permadi 2019) 


\section{B. Pelestarian Ceprotan}

Upacara tradisi Ceprotan hanya diselenggarakan satu tahun sekali pada bulan Longkang atau Selo dalam hitungan penggalan jawa, yaitu pada hari Senin Kliwon. Apabila dalam bulan Longkang atau Selo tidak terdapat hari Senin Kliwon, maka akan diadakan di hari Minggu Kliwon. Pelaksanaannya dimulai saat menjelang matahari terbenam.

Gambar. 2 (Suasana Upacara Adat Tradisi Ceprotan.

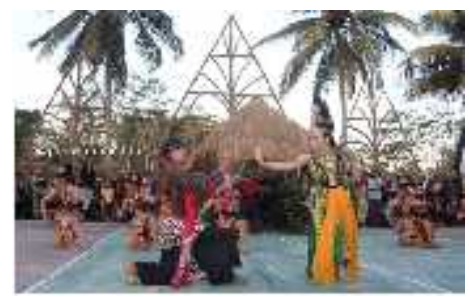

https://pacitankab.go.id/ceprotan-digelar-akhir-bulan-juli/ )

Tradisi ini mulai pertama kali dilaksanakan pada tahun 1981. saat pemerintahan desa di pimpin oleh Sakiman Sastro Wiyono tahun 1981-1999. Setelah Sakiman Sastro Wiyono selanjutnya pemerintahan di pimpin oleh Imam Tukidjo pada tahun 1999 sampai 2013. Pada periode Iman Tukidjo ini dalam pelaksanaan tradisi Ceprotan terjadi beberapa perubahan, diantaranya perubahan tempat penyelenggaraan yang sebelumnya diadakan di rumah Kepala Desa, karena minat dan antusiasme penonton dari kota dan luar kota yang tinggi pada tahun 2013 akhirnya tempat pelaksanaan upacara dipindahkan di Lapangan Desa Sekar. Namun dalam pelaksanaannya tetap sesuai tradisi sebelumnya. (Tradisi et al. 2015)

Kemudian pada 2013 pemerintahan desa berganti ke Miswandi. Pada masa kepemimpinan Miswandi tradisi ini semakin maju dan berkembang pesat terutama antusiasme penonton, terlihat banyak turis mancanegara yang juga ikut menonton acara ini, akhirnya ditambahkan hiburan - hiburan untuk semakin memeriahkan suasana mulai adanya peragaan Ki Godek dan Dewi Sekartaji, hiburan orkes dangdut dan ditutup oleh wayang purwa. Dalam pelaksanaannya acara ini berkembang dengan pesat tapi tata cara upacara ini tetap sesuai dengan standar dari pelaksanaan - pelaksanaan upacara terdahulu. (Tradisi et al. 2015) 


\section{Tanggapan dan Partisipasi Masyarakat}

Pada awalnya masyarakat belum begitu antusias dan tak sedikit masyarakat yang kurang setuju dengan tradisi bersih desa ini. Tetapi seiring berjalannya waktu masyarakat Desa Sekar dapat menerima dan bahkan sangat antusias dan juga menyambut dengan positif. Dengan diadakannya tradisi bersih desa ini masyarakat dapat melihat dan sekaligus berpartisipasi dalam tradisi bersih desa ini.

Gambar. 3 (Masyarakat menonton Tradisi Ceprotan yang sedang berlangsung.

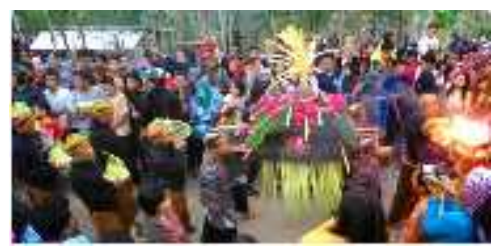

https://budayajawa.id/upacara-adat-ceprotan-daerah-donorojo-kabupaten-pacitan/)

Untuk masyarakat yang tidak ikut andil dalam tradisi ini mereka dapat menyaksikan tradisi ini dan sekaligus menjadi tontonan tersendiri dan tak jarang juga ada wisatawan asing yang datang melihat dalam Tradisi Ceprotan ini. Bagi masyarakat yang ikut berpartisipasi dalam tradisi ini merupakan prestasi tersendiri baginya. Disisi lain mereka menjaga tradisi dan adat istiadat agar tidak punah.

\section{Kebijakan Pemerintah Setempat Dalam Pelestarian Tradisi Ceprotan}

Indonesia adalah negara yang kaya dengan kesenian tradisional dan budaya masyarakat yang berbeda di setiap daerahnya. Sudah semestinya pemerintah berkewajiban untuk melindungi dan melestarikan warisan budaya. Pelestarian adalah upaya dinamis untuk mempertahankan keberadaan warisan budaya dan nilainya dengan cara melindungi, mengembangkan dan memanfaatkannya. Salah satu wujud tanggung jawab pemerintah dengan dikeluarkannya Peraturan Menteri Dan Kebudayaan Republik Indonesia Nomor 10 Tahun 2014 Tentang Pedoman Pelestarian Tradisi.

Pemerintah Pacitan diharapkan mampu menemukan cara bagaimana agar dapat memajukan daerahnya terutama melalui pelestarian warisan budaya yang ada. Untuk menindak lanjutinya dibuatlah kebijakan - kebijakan dalam hal urusan pengelolaan warisan budaya. Kesempatan terbuka lebar saat era otonomi daerah 
seperti ini karena pemerintah kota/kabupaten memiliki kuasa yang cukup besar untuk mengembangkan daerahnya sendiri. (Nunggalsari and Soebijantoro 2018) Kebijakan Pemerintah Desa Sekar dalam melestarikan tradisi budaya Ceprotan yaitu :

1. Pemerintah Desa Sekar menggelar rutin acara tradisi Ceprotan setiap setahun sekali.

2. Pemerintah Desa Sekar menyediakan informasi terkait tradisi Ceprotan.

3. Melakukan promosi untuk semakin menarik minat penonton.

4. Pemerintah Desa Sekar bekerja sama dengan Pemerintah Kecamatan Donorojo dan juga Pemerintah Kabupaten Pacitan.

5. Dalam penganggaran Pemerintah Desa Sekar menganggarkan dana untuk membiayai pelaksanaan kegiatan tradisi Ceprotan melalui APBDes dengan sumber dana ADD (Anggaran Dana Desa).

\section{KESIMPULAN}

Desa Sekar yang terletak di Kecamatan Donorojo Kabupaten Pacitan merupakan salah satu desa yang mempunyai kebudayaan dan tradisi. Tidak semua desa di Kabupaten Pacitan mempunyai kebudayaan dan tradisi, maka dari itu Pemerintah Desa Sekar harus menjaga dan melestarikan melalui kebijakankebijakannya supaya tradisi Ceprotan tidak punah.

Tradisi Ceprotan yaitu tradisi bersih desa yang diadakan setiap setahun sekali tepatnya pada setiap bulan Longkang atau Selo (DzulQa'adah / Dulkangidah) di hari pasaran Senin Kliwon atau pada hari pasaran Minggu Kliwon pelaksanaannya dilakukan pada saat menjelang mata hari terbenam atau surup dalam istilah jawa.

Selain itu tradisi Ceprotan ini dilaksanakan untuk mengenang dan menghormati para pendahulu Desa Sekar, yaitu Panji Asmorobangun dan Dewi Sekartaji yang diyakini tradisi ini dapat menjauhkan Desa Sekar menolak bala/marabahaya dan menjauhkan dari prasangka buruk serta memperlancar hasil pertanian yang menjadi mata pencaharian dan penghasilan utama penduduk setempat 


\section{DAFTAR PUSTAKA}

Apriliani Fitria, Nurul, and Gading Aniriani Wilda. 2017. "Seminar Nasional Hasil Penelitian Universitas Kanjuruhan Malang 2017." Penegakan Hak Asasi; Forum Anak; Daya Saing Bangsa 34 (46): 661-70.

Edward Burnett, Tylor. 1871. Primitive Culture: Researches Into the Development of Mythology, Philosophy, Religion, Art, and Custom, Volume 1.

Ika Monika. 2017. "Kebijakan Pemerintah Daerah Dalam Pelestarian Kesenian Tradisional Di Kota Makassar." GOVERNMENT: Jurnal Ilmu Pemerintahan 42 (1): 89-96. journal.unhas.ac.id.

Nunggalsari, Rizky Nindya, and Soebijantoro Soebijantoro. 2018. "Kebijakan Pemerintah Kabupaten Pacitan Dalam Pelestarian Museum Buwono Keling Di Kecamatan Punung Kabupaten Pacitan." Agastya: Jurnal $\begin{array}{lllll}\text { Sejarah Dan Pembelajarannya } & 8 & \text { (01): } & 75 .\end{array}$ https://doi.org/10.25273/ajsp.v8i01.2037.

Permadi, Topan Bagus. 2019. "Peristiwa Sebagai Seni Evaluasi Terhadap Tradisi Budaya Pacitan," no. September.

Pesantren, Institut, K H Abdul, and Chalim Pacet. 2019. "Tradisi Slametan Jawa Dalam Perspektif Pendidikan Islam” 15 (September): 93-107.

Rahmawati, Yulfrida. 2015. "Pengenalan Budaya Melalui Bercerita Untuk Anak Usia Dini." Jurnal Pendidikan Anak 1 (1).

Robert, Sibarani. 2015. "Pendekatan Antropolinguistik Terhadap Kajian Tradisi Lisan." RETORIKA: Jurnal Ilmu Bahasa 1 (1): 94-107. https://doi.org/10.22225/jr.1.1.105.1-17.

Tradisi, Perkembangan, Ceprotan Di, Desa Sekar, and Kecamatan Donorojo. 2015. "AVATARA, e-Journal Pendidikan Sejarah" 3 (3): 469-79.

Utara, Universitas Sumatera. 2008. "Yaitu Bentuk Jamak Dari Kata,” 2-3. 